Research Article

\title{
A Switched-Reluctance Motor Drive Powered by Switch-Mode Rectifier with Battery Energy Storage Buffer
}

\author{
Chen-Wei Yang, Min-Ze Lu, Wei-Ming Ma, Chang-Ming Liaw *
}

National Tsing Hua University, No. 101, Sec. 2, Guangfu Rd., East Dist., Hsinchu City, Taiwan (R.O.C.); E-Mails: real913223kg@gmail.com; b10112016@gmail.com; ma10101994@yahoo.com.tw; cmliaw@ee.nthu.edu.tw

* Correspondence: Chang-Ming Liaw; E-Mail: cmliaw@ee.nthu.edu.tw

Academic Editor: Aritra Ghosh

Special Issue: Progress of Wind Energy Technology and Its Maintenance

Journal of Energy and Power Technology

2021, volume 3, issue 2

doi:10.21926/jept.2102016
Received: December 23, 2020

Accepted: March 21, 2021

Published: April 07, 2021

\begin{abstract}
This paper presents a three-phase full-bridge boost switch-mode rectifier (SMR) powered switched-reluctance motor (SRM) drive with battery energy storage buffer. It covers the designing of the power circuits and control schemes for the two power stages. Except for having a superior line-drawn power quality, the boost-able DC-link voltage of the SRM drive can enhance the SRM driving performance in a wide speed range and sent back the recovered regenerative braking energy to the grid successfully. The next is establishing a battery energy storage system (BESS) with a bidirectional interface DC-DC converter connected to the motor drive DC-link for providing an energy buffer. The proposed parallel operation strategy has three possible inter-connected operations. (i) Grid-to-battery (G2B) charging: The battery charged by the grid with a good line drawn power quality. (ii) B2G discharging operation: The battery sending power back to the grid by the interface converter and the SMR. (iii) Battery buffer operation: Powering of the SRM drive simultaneously by the utility grid and the battery with the proposed parallel operation strategy.
\end{abstract}

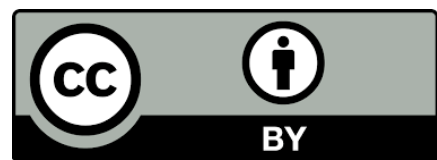

(C) 2021 by the author. This is an open access article distributed under the conditions of the Creative Commons by Attribution License, which permits unrestricted use, distribution, and reproduction in any medium or format, provided the original work is correctly cited. 


\section{Keywords}

Switched-reluctance motor; switch-mode rectifier; battery energy storage system; parallel operation

\section{Introduction}

Electric motors are the crucial actuators in various industrial plants and electric vehicles [1-3]. DC motor, induction motor, and permanent-magnet synchronous motor (PMSM) remain the mainstream actuators most commonly used due to inherent mature technologies and easily accessible commercial components. However, SRM [4] has the most potential to be the competitor in various speed driving applications [4-7] due to the merits, including simple structure with singlyexcited concentrated armature winding, the rotor without conductors or magnets providing rigidity and no demagnetization risk of the permanent magnet, highly developed torque, and acceleration capability. Thereby, it is suitable for harsh environments and high-speed driving conditions. However, SRM also has a few drawbacks, including the nonlinear winding inductance rendering the nonlinear torque development and dynamic behavior, the adverse effects of back electromotive force (EMF) on the winding current control performance, higher torque ripple, higher vibration, and acoustic noise. Thus, it is imperative to develop some novel technologies for driving performance enhancement and applicability promotion.

In order to establish a high-performance SRM drive, one needs to adopt a proper power converter and suitable switching control scheme to yield the desired winding current. The details on SRM converters have been described earlier [8,9]. Among the converters, the standard asymmetric bridge converter has $2 \mathrm{~N}(\mathrm{~N}=$ phase number) switches and diodes, possesses the most flexible PWM switching capability for driving and regenerative braking operation. Hence it was adopted in the current study.

For a motor drive powered from the mains, the adjustable DC-link voltage can be established by employing SMR as the AC/DC front-end converter. The systematic reviews on the existing and most commonly used three-phase SMRs have been published elsewhere [10-18]. For bidirectional power flow, the application of the four-quadrant three-phase six-switch (3P6SW) SMR is necessary. On the other hand, the motor drive powered by DC sources with bidirectional powers requires a suitable bilateral interface DC/DC front-end converter [19-22]. Hence, the developed battery energy storage system adopts the one-leg bidirectional boost-buck converter [21].

Multiple sources and energy storage devices are vital in enhancing the energy supplying reliability for many industrial plants. Nadeem et al. [23] discussed the comparative features of various energy storage devices and respective specific applications. Some usual applications include microgrid [23, 24], Electric Vehicle (EV) [25-28], elevator [29], etc. In EV applications, adding a suited super-capacitor (SC) can enhance the energy conversion performance of the fuel-cell $[25,26]$ or battery $[27,28]$. In order to enhance both DC-link voltage restoration and effective power-sharing between the battery and the SC, an earlier study [30] proposed a joint control strategy based on the uncompensated battery power.

This paper makes three main contributions to the field. The first is establishing and testing an SMR-fed three-phase full-bridge, and then designing control schemes for the SRM drive. The next is 
using proportional-resonant (PR) type current controllers to enhance the current responses in the full-bridge SMR. The last is using the proposed parallel operation strategy to develop the SMR-fed SRM drive with a battery energy buffer, which can power the SRM drive by the utility grid and the battery simultaneously to enhance the energy supplying reliability.

\section{System Configuration and Functional Descriptions}

Figure 1 illustrates the system configuration and the detailed schematic of the established SMRfed SRM drive with battery energy storage buffer along with the actual image of the SRM-PMSG set. Further, Figure 1 indicates the correspondence between the standard SRM asymmetric converter schematic and the realized circuit using off-the-shelf IGBT modules. The powering of the SRM drive is mainly by the utility through the SMR, while the battery provides the energy buffer of the motor drive DC-link.
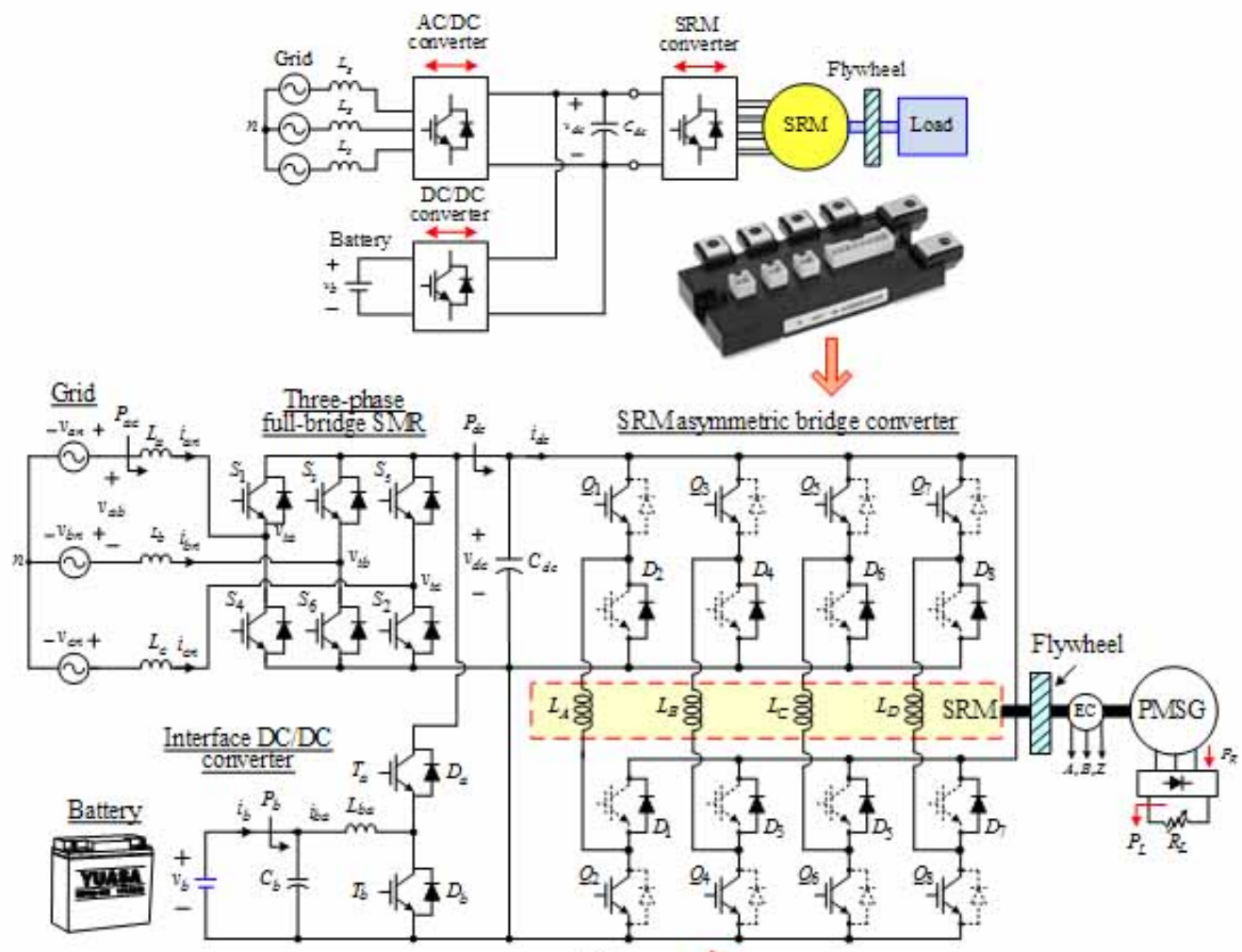

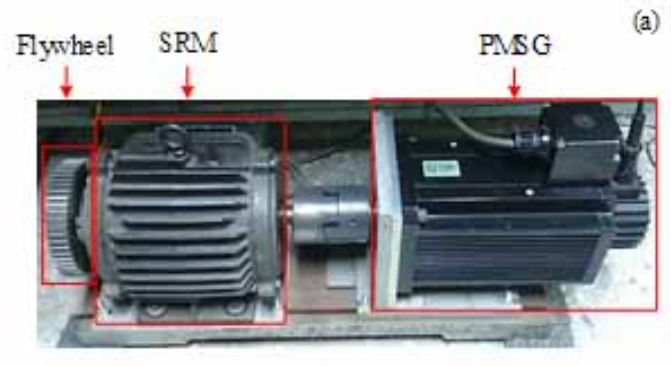

(b)

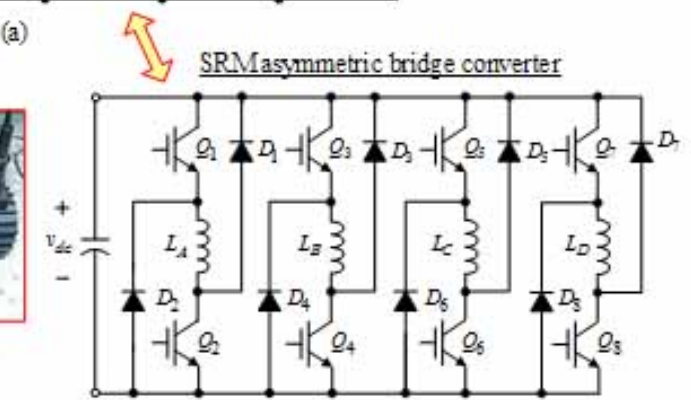

(c)

Figure 1 The developed SMR-fed SRM drive with energy storage buffer: (a) System block and power circuit; (b) Experimental SRM-PMSG test bench; (c) Developed SRM asymmetric bridge converter using two 7-pack IGBT modules. 
Figure 2(a), Figure 2(b), and Figure 2(c) depict the control schemes of the SRM drive, the SMR, and the battery interface converters, respectively. For industrial applications with weak power systems, the proposed control strategy can enhance the power supplying. A brief discussion on possible operations of the developed SRM drive is given below.

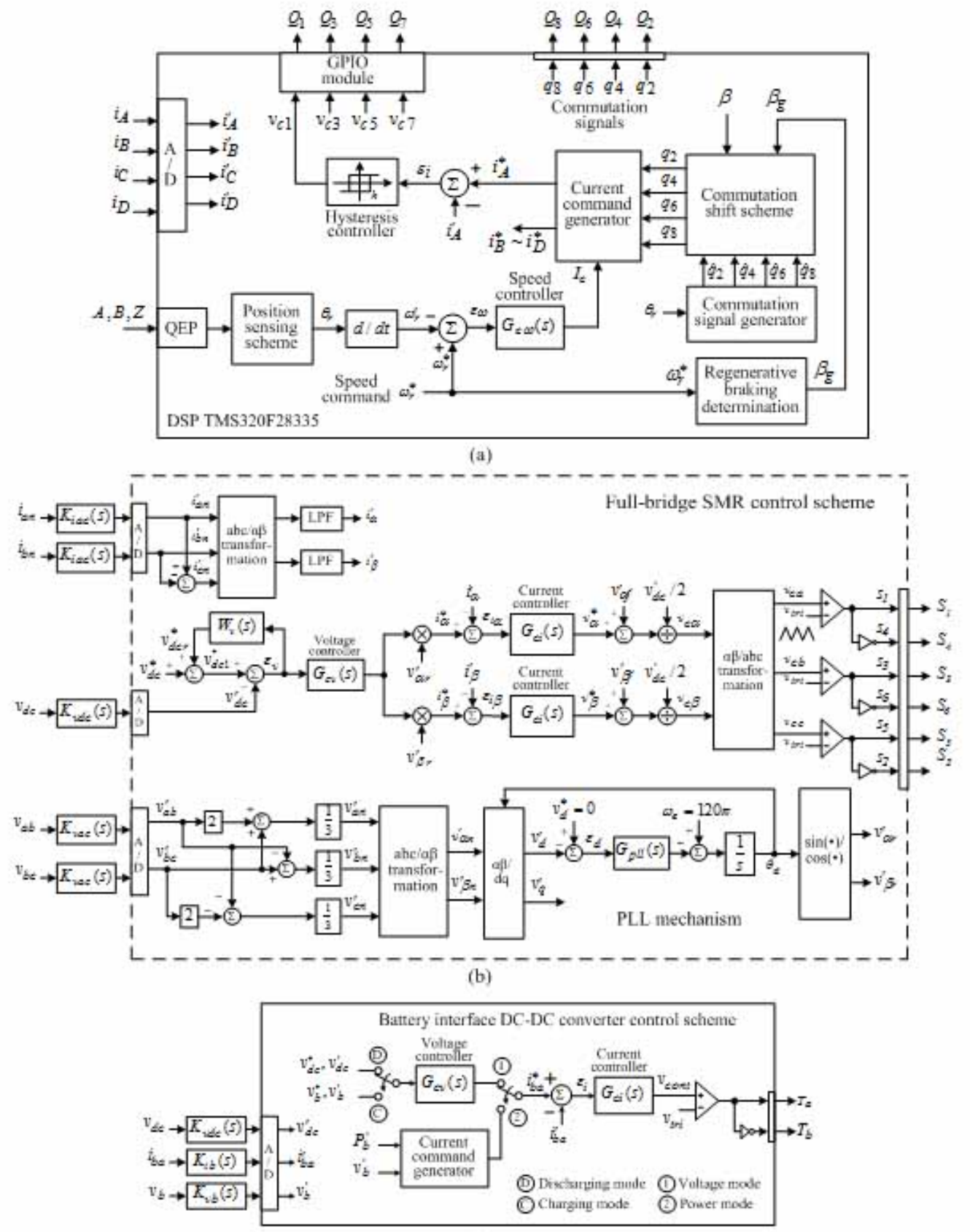

(c)

Figure 2 Control schemes: (a) SRM drive; (b) Three-phase full-bridge SMR; (c) Battery interface DC-DC converter.

\subsection{Three-Phase Full-Bridge SMR}

The SMR with the energy storage buffer can perform the G2B charging operation or power the SRM drive with a battery energy buffer. 


\subsection{Battery Interface DC/DC Converter}

\subsubsection{Discharging Mode}

The battery can establish a well-regulated DC-link voltage to power the SRM drive independently. The availability of utility power can control the battery to assist the SMR-fed SRM drive or perform the B2G operation of sending power back to the utility grid if the battery output power is higher than the requirement of the SRM drive.

\subsubsection{Charging Mode}

There are two situations for battery charging: (1) G2B operation from the utility grid; (2) Regenerative braking operation of the battery-fed SRM drive.

\subsection{SRM Drive}

In driving mode, the SRM drive can be powered from the mains via the SMR or the battery. In regenerative braking, the recovered power can be sent back to the grid or the battery. A small flywheel is added to the studied SRM shaft to increase the stored kinetic energy. The normal regenerative braking operation with energy being successfully sent back to the mains can be verified by the results presented in Figure 3 of Sec. 4.2. However, due to insufficiently large stored energy, the steady-state characteristics, including the recovered energy percentage, cannot be measured for the short operation period.

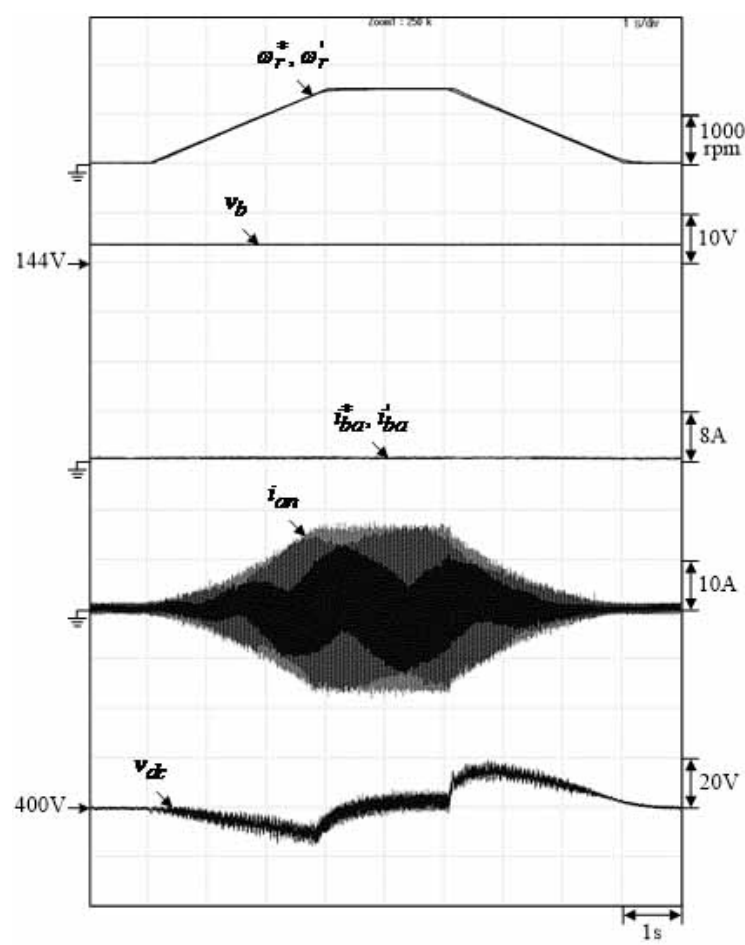

Figure 3 Measured $\left(w_{r}^{*}, w_{r}^{\prime}\right), v_{b},\left(i_{b a}^{*}, i_{b a}^{\prime}\right), i_{a n}$, and $v_{d c}$ of the SMR-fed SRM drive without energy storage buffer with $v^{*}{ }_{d c}=400 \mathrm{~V}, R_{L}=7.1 \Omega$, and $B=6^{\circ}$ due to ramp speed command change of $w^{*}{ }_{r}=0 \mathrm{rpm} \rightarrow 1500 \mathrm{rpm} \rightarrow 0 \mathrm{rpm}$ with both rising rate and falling rate of $500 \mathrm{rpm} / \mathrm{s}$. 


\section{The Constituted Power Stages}

\subsection{SRM Drive}

\subsubsection{Power Circuit}

(1) SRM-PMSG set:

- SRM: Four-phase, $8 / 6$ teeth, 400V, 4 kW, 1500rpm (TASC Drives Ltd. UK).

- PMSG: Three-phase, 24A, $4.5 \mathrm{~kW}, 2000 \mathrm{rpm}$, with adjustable load resistance $R_{L}$.

- Flywheel: $J=0.01845 \mathrm{~kg} \mathrm{~m}^{2}$.

(2) Asymmetrical bridge converter: Formed by two IGBT modules CM100RL-12NF(Mitsubishi).

\subsubsection{Control Schemes}

The sampling rate of the current loop and speed loop is $16 \mathrm{kHz}$ and $800 \mathrm{~Hz}$, respectively.

(1) Current control scheme

- Current sensing factor: The sensing factor is set as 0.04V/A.

- Hysteresis current control PWM (HCCPWM): Using the HCCPWM scheme with the current hysteresis band is set as $h=0.01 / C$ to counteract the effects of back-EMF effectively.

(2) Speed control scheme

- The set PI feedback controller $G_{C \omega}(s)$ is as follows:

$$
G_{c \omega}(s)=K_{P \omega}+\frac{K_{I \omega}}{s}=14.1+\frac{32.1}{s}
$$

(3) Commutation shift scheme

The application of the advanced commutation shift can reduce the effects of back-EMF. The resolution of shift angle is $N_{o s}=1$ corresponding to $B=0.036^{\circ}$. To achieve regenerative braking, setting the backward-shift at $B_{g}=-15^{\circ}$ allows allocation of the SRM winding current in the negative inductance slope region.

\subsection{Three-Phase Full-Bridge SMR}

\subsubsection{System Configuration and Parameters}

- Three-phase AC input line voltage: The line-to-line RMS voltage $V_{a b}=220 \mathrm{~V} / 60 \mathrm{~Hz}$.

- DC-link voltage: $V_{d c}=400 \mathrm{~V}$.

- Power rating: $P_{d c}=4 \mathrm{~kW}$.

- Switching frequency: $f_{s}=16 \mathrm{kHz}$.

- Output filtering capacitor: Serially connected capacitors with $C_{d c}=3300 \mu \mathrm{F} / 2=1650 \mu \mathrm{F}$.

- Input energy storage inductors:

(i) $60 \mathrm{~Hz}: L_{a}=1.519 \mathrm{mH}, L_{b}=1.497 \mathrm{mH}, L_{c}=1.534 \mathrm{mH}$.

(ii) $16 \mathrm{kHz}: L_{a}=1.127 \mathrm{mH}, L_{b}=1.126 \mathrm{mH}, L_{c}=1.127 \mathrm{mH}$.

- Power devices: IGBT module CM100DY-12H.

\subsubsection{Control Schemes}


(i) Phase-lock-loop mechanism

- Figure 2(b) shows the established SMR synchronously connected to the grid through the phase-lock-loop (PLL) mechanism.

- Voltage sensing factor: $K_{\text {vac }}=1 \mathrm{mV} / \mathrm{V}$.

- The selected PI controller $G_{p l l}(s)$ is as follows:

$$
G_{p l l}(s)=20+\frac{64000}{s}
$$

(ii) Current control scheme

- Current sensing factor: $K_{i a c}=0.02 \mathrm{~V} / \mathrm{A}$.

- Proportional-plus-resonant (PR) feedback controller $G_{C i}(s)$ is set as follows:

$$
G_{c i}(s)=K_{P i}+\frac{K_{R i} s}{s^{2}+\omega_{o}{ }^{2}}=0.8+\frac{125 s}{s^{2}+(2 \pi 60)^{2}}
$$

(iii) Voltage control scheme

- Voltage sensing factor: $K_{v a c}=1 \mathrm{mV} / \mathrm{V}$ and $K_{v d c}=1.667 \mathrm{mV} / \mathrm{V}$.

- The PI feedback controller $G_{C V}(s)$ is set as follows:

$$
G_{c v}(s)=K_{P v}+\frac{K_{I v}}{s}=4.5+\frac{396}{s}
$$

- Voltage Robust Error Cancellation Controller (VRECC):

$$
W_{v}(s)=\frac{W_{v}}{1+\tau_{v} s} \approx W_{v}, 0 \leq W_{v} \leq 1
$$

Here $W_{v}=0.5$.

\subsection{Battery Interface DC/DC Converter}

\subsubsection{Power Circuit}

(i) Battery discharging

- Ratings: $V_{d c}=400 \mathrm{~V}, P_{d c}=4 \mathrm{~kW}, f_{s}=16 \mathrm{kHz}$.

- Battery bank: Twelve cells (YUASA REC22-12B, 12V-22Ah) with nominal voltage $V_{b}=144 \mathrm{~V}$.

- In boost CCM mode: $V_{d c} / V_{b}=1 /(1-D)$, the duty ratio is $D=0.64$, and the rated average output current is $I_{d c}=P_{d c} / V_{d c}=10 \mathrm{~A}$. Hence, the average inductor current $I_{b a}=P_{d c} / V_{b}=27.78 \mathrm{~A}$, the average diode current $I_{D}=I_{d c}=10 \mathrm{~A}$, and the average switch current $I_{S}=D I_{b a}=17.78 \mathrm{~A}$.

- Considering the large inductor current and saturation effect of the employed toroidal core T400-26D (Micro-metals), the set turn number is $N=63$, and winding is done using conductor AWG\#14. The inductance measured at $16 \mathrm{kHz}$ is $L_{b a}=1 \mathrm{mH}$.

(ii) Battery charging

- The nominal DC-link voltage is $400 \mathrm{~V}$. The maximum charging current of the battery is $I_{b a}=$ $5 \mathrm{~A}$ and the charging voltage command $v_{b}^{*}$ is $170 \mathrm{~V}$. Hence, the rated powers of the battery and DClink are $P_{b}=P_{d c}=144 \times 5=720 \mathrm{~W}$, and the DC-link current is $I_{d c}=P_{d c} / V_{d c}=1.8 \mathrm{~A}$. 
- For $V_{b} / V_{d c}=D$, the duty ratio is $D=0.36$. Hence, the current and voltage ratings of the power devices are $I_{b a}=5 \mathrm{~A}, I_{S}=D I_{b a}=1.8 \mathrm{~A}, I_{D}=(1-D) I_{b a}=3.2 \mathrm{~A}, \Delta i_{b a}=5.76 \mathrm{~A}, i_{b a, \max }=i_{S, \max }=i_{D, \max }=7.88 \mathrm{~A}$, $\mathrm{V}_{S, \max }=v_{D, \max }=400 \mathrm{~V}$.

- $\quad$ Filtering capacitors: $C_{d c}=1650 \mu \mathrm{F} / 800 \mathrm{~V}$ and $C_{b}=940 \mu \mathrm{F} / 1000 \mathrm{~V}$.

- Power devices: IGBT module CM100DY-12H.

\subsubsection{Control Schemes}

As the bidirectional interface converter frequently operates in boost mode for discharging, the control scheme designing is under this mode. Besides, the designed control scheme is suited for the buck converter for charging.

(i) Current control scheme

- Current sensing factor: $K_{i b a}=15.15 \mathrm{mV} / \mathrm{A}$.

- The set PI feedback controller $G_{C i}(s)$ is as follows:

$$
G_{c i}(s)=K_{P i}+\frac{K_{I i}}{s}=0.55+\frac{56}{s}
$$

(ii) Voltage control scheme

- Voltage sensing factor: $K_{v b}=3.33 \mathrm{mV} / \mathrm{V}$ and $K_{v d c}=1.667 \mathrm{mV} / \mathrm{V}$.

- The set PI feedback controller $G_{C V}(s)$ is as follows:

$$
G_{c v}(s)=K_{P v}+\frac{K_{I v}}{s}=10+\frac{500}{s}
$$

\section{Experimental Results}

\subsection{G2B/B2G Operations}

\subsubsection{G2B Operation}

Figure 1 and Figure 2(b) depict the three-phase AC source $220 \mathrm{~V} / 60 \mathrm{~Hz}$ and the DC-link voltage command $v^{*}{ }_{d c}=400 \mathrm{~V}$ are set by the SMR. The battery charging current command $l^{*}{ }_{b a}=0.23 \mathrm{C} \cong 5 \mathrm{~A}$. Figure 4(a), Figure 4(b), Figure 4(c) and Figure 4(d) shows the measured $\left(v_{d c}, v_{a n}, i_{a n}\right),\left(i_{a n}, i_{b n}, i_{c n}\right),\left(v_{b}\right.$, $\left.i_{b}\right)$, and $i_{b a}$ for the normal operation of the established SMR and BESS. The results demonstrate the establishment of a well-regulated DC-link voltage from the utility grid with good line-drawn power quality. The interface DC/DC converter-based charger achieves good battery charging characteristics, as enlisted in Table 1. 


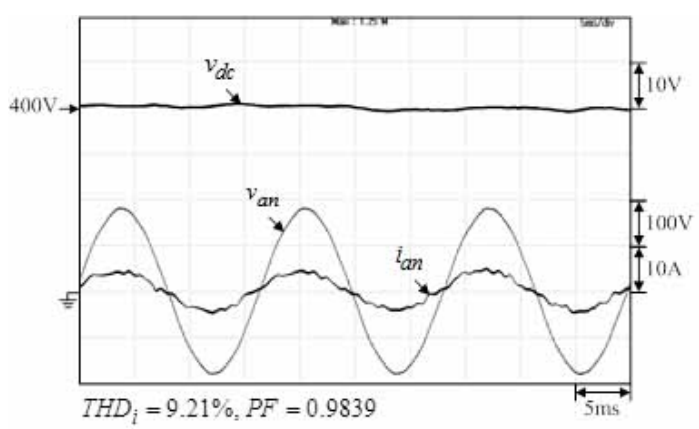

(a)
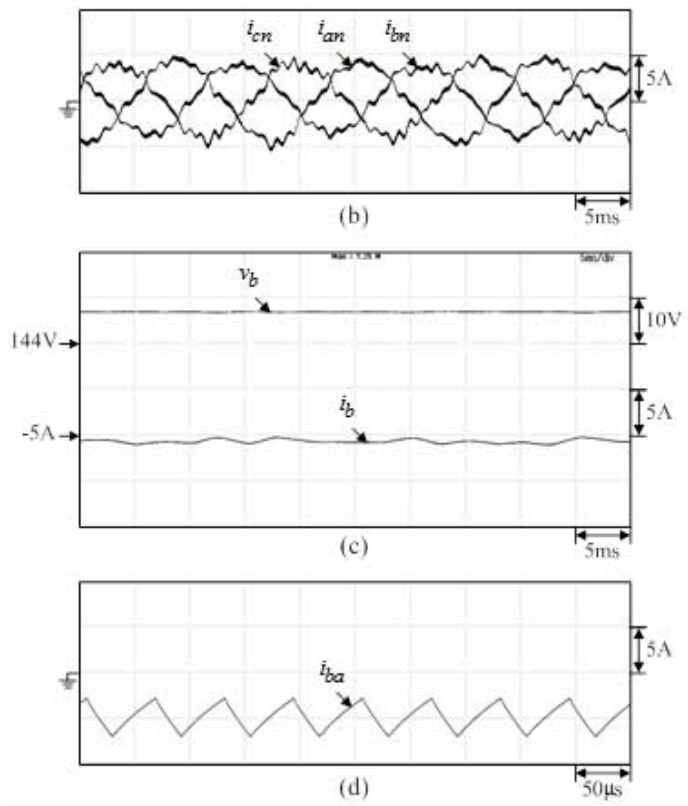

Figure 4 Measured results of the established three-phase full-bridge boost SMR based charger in G2B operation at $I_{b}=5 \mathrm{~A}, v^{*}{ }_{b}=170 \mathrm{~V}, v_{d c}^{*}=400 \mathrm{~V}$, and $V_{a c}=220 \mathrm{~V} / 60 \mathrm{~Hz}$ : (a) $\left(v_{d c}\right.$, $\left.v_{a n}, i_{a n}\right) ;(\mathrm{b})\left(i_{a n}, i_{b n}, i_{c n}\right) ;(\mathrm{c})\left(v_{b}, i_{b}\right)$; and (d) $i_{b a}$.

Table 1 Measured steady-state characteristics of the developed three-phase full-bridge boost SMR based charger under constant charging current.

\begin{tabular}{lllllll}
\hline \multicolumn{6}{c}{$V_{a c}=220 \mathrm{~V} / 60 \mathrm{~Hz}, V_{d c}=400 \mathrm{~V}, V_{b}=151.49 \mathrm{~V}, I_{b}=5.34 \mathrm{~A}$} \\
& $i_{a n}$ & $i_{b n}$ & $i_{c n}$ & $P_{a c}(\mathrm{~W})$ & $P_{b}(\mathrm{~W})$ & $\eta_{1}(\%)^{*}$ \\
\hline rms value (A) & 2.64 & 2.43 & 2.52 & & & \\
$T H D_{i}(\%)$ & 9.21 & 10.85 & 9.13 & 944.5 & 808.6 & 85.61 \\
$P F$ & 0.9839 & 0.9851 & 0.9750 & & \\
\hline \multicolumn{6}{c}{$\eta_{1} \triangleq P_{b} / P_{a c}$}
\end{tabular}

\subsubsection{B2G Operation}

The B2G operation requires setting the three-phase AC source $220 \mathrm{~V} / 60 \mathrm{~Hz}$ and the DC-link voltage command $v^{*}{ }_{d c}=400 \mathrm{~V}$. The well-controlled battery and interface converter are the current sources with the current command generated from the outer power control loop, and the SMR 
operates as a grid-connected inverter. Figure 5 depicts the measured $\left(v_{d c}, v_{a n}, i_{a n}\right),\left(i_{a n}, i_{b n}, i_{c n}\right),\left(v_{b}\right.$, $\left.i_{b}\right)$, and $i_{b a}$ obtained by commanding the battery output power $P_{b}=3000 \mathrm{~W}$. The results demonstrate the establishment of the well-regulated DC-link voltage. Further, the battery supplies real power to the grid by the interface converter and the three-phase grid-connected inverter. The current directions of $i_{b}$ and $i_{a n}$ indicate normal power flow operations of the two power stages, and Table 2 enlists the corresponding steady-state characteristics.

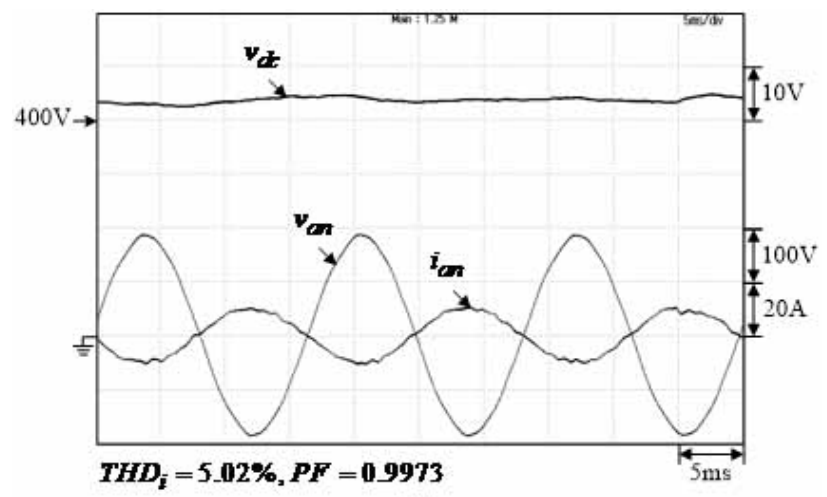

(a)
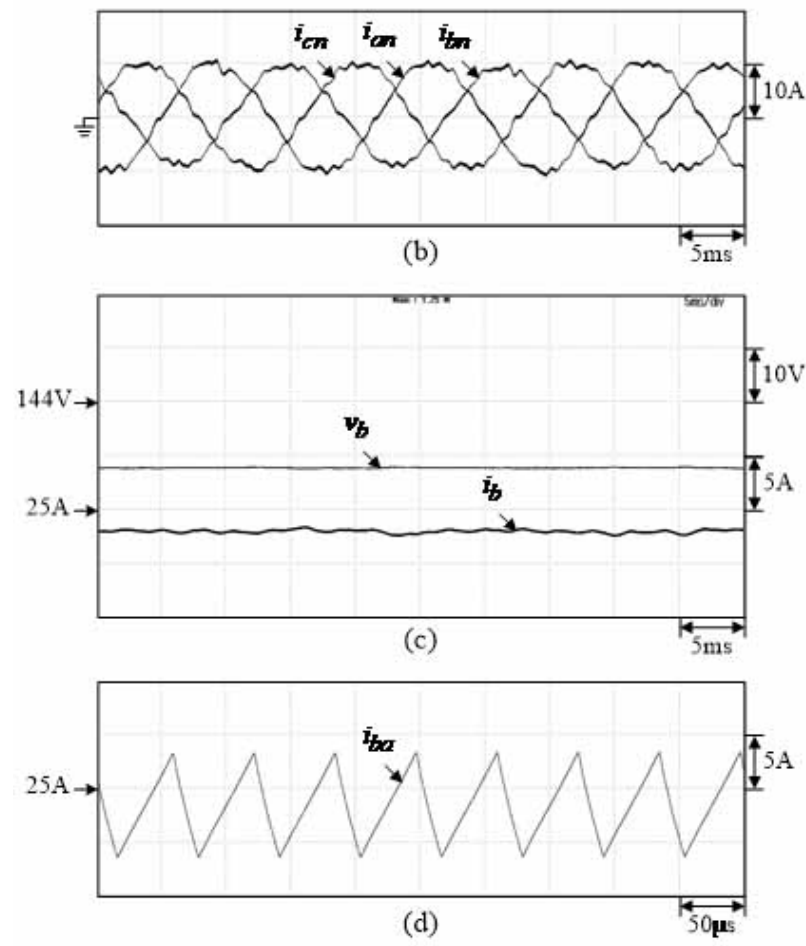

Figure 5 Measured results of the established three-phase grid-connected inverter in B2G operation at $P_{b}=3000 \mathrm{~W}, v_{d c}^{*}=400 \mathrm{~V}$, and $V_{a c}=220 \mathrm{~V} / 60 \mathrm{~Hz}$ : (a) $\left(v_{d c}, v_{a n}, i_{a n}\right) ;(\mathrm{b})\left(i_{a n}, i_{b n}\right.$, $\left.i_{c n}\right) ;(\mathrm{c})\left(v_{b}, i_{b}\right) ;$ and $(\mathrm{d}) i_{b a}$.

Table 2 Measured steady-state characteristics of the three-phase grid-connected inverter operated for constant battery output power.

\begin{tabular}{llllll}
\hline$V_{a c}=220 \mathrm{~V} / 60 \mathrm{~Hz}, v_{d c}=400 \mathrm{~V}, V_{b}=134.40 \mathrm{~V}, I_{b}=22.52 \mathrm{~A}$ & \\
\hline$i_{a n}$ & $i_{b n}$ & $i_{c n}$ & $P_{a c}(\mathrm{~W})$ & $P_{b}(\mathrm{~W})$ & $\eta_{2}(\%)^{*}$
\end{tabular}




\begin{tabular}{lllllll} 
rms value (A) & 6.99 & 6.83 & 6.96 & & & \\
$T H D_{i}(\%)$ & 5.02 & 4.81 & 3.86 & 2700.0 & 3026.8 & 89.20 \\
$P F$ & 0.9973 & 0.9968 & 0.9964 & & & \\
\hline \multicolumn{7}{c}{$\eta_{2} \triangleq P_{a c} / P_{b}}$.
\end{tabular}

\subsection{SMR-fed SRM Drive with Energy Storage Buffer}

The power circuits and control schemes of the developed SMR-fed SRM drive with energy storage buffer, as referred to in Figure 1 and Figure 2 . The battery with interface converter is well-controlled to be a current source, and the three-phase full-bridge SMR is in charge of regulating the DC-link voltage. Commanding the batteries can ensure a judicious power supply to provide energy support. As the battery energy is deficient, the utility grid can power the SRM drive by the three-phase SMR while recharging the battery.

The characteristic observation was from the two arranged scenarios of the developed SMR-fed SRM Drive under different battery outputs for the following experimental results, with all the settings emphasizing supplying power to the SRM drive.

\subsubsection{Case 1: Parallel Operation Characteristics of SMR and Battery for SRM Drive}

Figure 6 shows the measured $w_{r}^{\prime}, I_{c}, v_{b},\left(i_{b a}^{*} i^{\prime}{ }_{b a}\right), i_{a n}$ and $v_{d c}$ of the developed SRM drive with energy storage buffer under $w^{*}{ }_{r}=1000 \mathrm{rpm}, v^{*}{ }_{d c}=400 \mathrm{~V}, R_{L}=7.1 \Omega$, and $B=4.5^{\circ}$. The arranged scenarios are as follows:

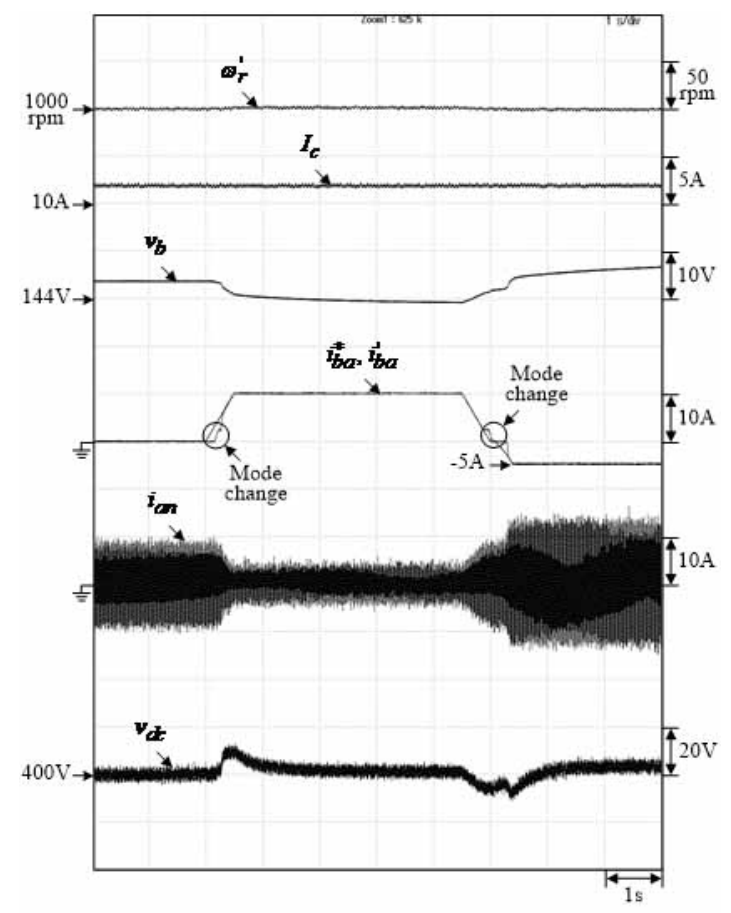

Figure 6 Measured $w_{r}^{\prime}, I_{c}, v_{b},\left(i^{*}{ }_{b a}, i_{b a}^{\prime}\right), i_{a n}$ and $v_{d c}$ of the SMR-fed SRM drive with energy storage buffer at $w^{*}{ }_{r}=1000 \mathrm{rpm}, v^{*}{ }_{d c}=400 \mathrm{~V}, R_{L}=7.1 \Omega$, and $B=4.5^{\circ}$ under the parallel operation of SMR and battery. 
(i) Disabling of the battery energy buffer so the utility grid fully powers the SRM drive by the three-phase SMR.

(ii) Enabling the energy buffer and setting the current command $i^{*}{ }_{b a}$ to $10 \mathrm{~A}$ with the rising rate of $20 \mathrm{~A} / \mathrm{s}$ directly. The results demonstrate first, no impact on both the resulting winding current command and SRM drive speed, second, the SMR automatically reduces the power supplied from the utility grid to regulate the DC-link voltage, and the third is the presence of only a slight DC-link voltage deviation (lower than 15V).

(iii) Let $i_{b a}^{*}$ decrease from $10 \mathrm{~A} \rightarrow 0 \mathrm{~A}$ with falling rate of $20 \mathrm{~A} / \mathrm{s}$. Similarly, the SMR gradually increases the power supplied from the mains as per the requirements of the SRM drive.

(iiii) Finally, the G2B operation is conducted, where the battery is charged at 5A. Moreover, the power for the SRM drive and the battery charging is entirely provided from the utility grid via the SMR.

\subsubsection{Case 2: The Developed SMR-fed SRM Drive without/with Battery Energy Buffer}

To evaluate the effects of the energy storage buffer on the SMR-fed SRM drive, the motor operation ranges from $0 \mathrm{rpm} \rightarrow 1500 \mathrm{rpm} \rightarrow 0 \mathrm{rpm}$ with an acceleration/deceleration rate of 500 rpm/s at $R_{L}=7.1 \Omega$ and $B=6^{\circ}$. The measured results $\left(w^{*}{ }_{r}, w_{r}{ }_{r}\right), v_{b},\left(i^{*}{ }_{b a}, i^{\prime}{ }_{b a}\right), i_{a n}$ and $v_{d c}$ are for the developed SMR-fed SRM drive without/with energy storage buffer under the same working conditions.

(i) SRM drive only powered by the utility grid. Figure 3 depicts the experimental results of the SMR-fed SRM drive without a battery energy storage buffer. The disabling of the energy storage buffer allows the utility grid to supply the SRM drive alone. Notably, the DC-link voltage deviation is near $\pm 18 \mathrm{~V}$. Figure 3 shows an $v_{d c}$ increase during the decelerating period, which can verify the correctness of the SRM regenerative braking operation. The $P_{d c}$ estimation is by the sensed DC-link voltage $v_{d c}^{\prime}$ and the observed DC-link current $\hat{i}_{d c}$. The $\hat{i}_{d c}$ synthesis is from the SRM winding currents and the corresponding switching signals. Figure 7 depicts the measured $i_{d c}$ and observed $\hat{i}_{d c}$ at $v_{d c}=$ $400 \mathrm{~V}, w_{r}^{*}=1500 \mathrm{rpm}, R_{L}=7.1 \Omega$, and $B=6^{\circ}$.

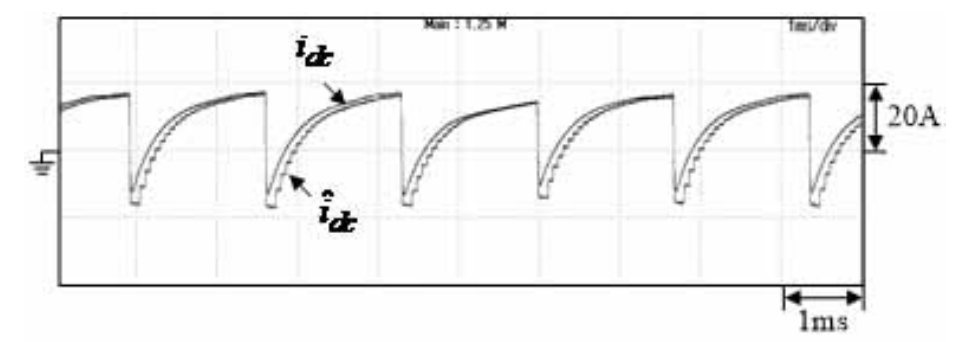

Figure 7 Measured DC-link current $i_{d c}$ and the observed one $\hat{i}_{d c}$ of the established SMRfed SRM drive at $\left(v_{d c}=400 \mathrm{~V}, w^{*}{ }_{r}=1500 \mathrm{rpm}\right.$, and $\left.R_{L}=7.1 \Omega, B=6^{\circ}\right)$.

(ii) SRM drive powered by utility and battery. Figure 8 depicts the measured results of the SMRfed SRM drive with the battery energy storage buffer, where the set battery output power is $P_{b}=$ $0.5 P_{d c}$. Figure 3 and Figure 8 demonstrated that the DC-link voltage deviation smaller than $\pm 10 \mathrm{~V}$ with the energy storage buffer. The energy buffer enabling reduces the magnitude $i_{a n}$ in half to the 
original one indicating that the battery and the grid simultaneously power the SRM drive with good sharing characteristics $\left(P_{b}=0.5 P_{d c}\right)$.

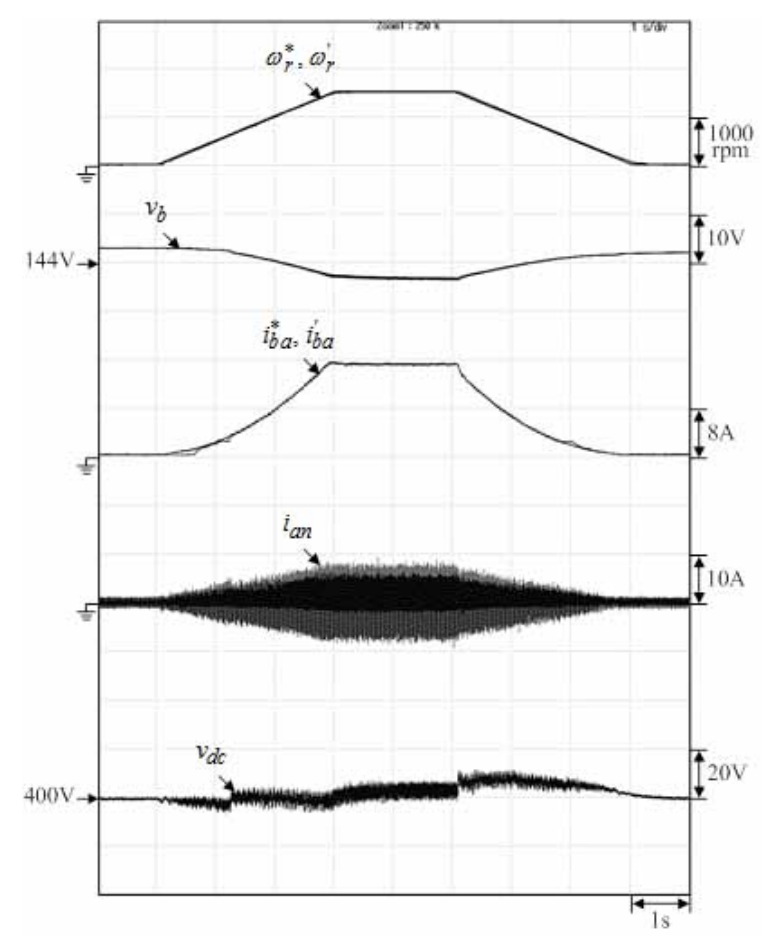

Figure 8 Measured $\left(w^{*}{ }_{r}, w_{r}^{\prime}\right), v_{b},\left(i^{*}{ }_{b a}, i_{b a}^{\prime}\right), i_{a n}$, and $v_{d c}$ of the SMR-fed SRM drive with energy storage buffer at $v^{*}{ }_{d c}=400 \mathrm{~V}, R_{L}=7.1 \Omega$, and $B=6^{\circ}$ due to ramp speed command change of $w^{*}{ }_{r}=0 \mathrm{rpm} \rightarrow 1500 \mathrm{rpm} \rightarrow 0 \mathrm{rpm}$ with both rising rate and falling rate of $500 \mathrm{rpm} / \mathrm{s}$.

\section{Conclusions}

The use of bidirectional SMR can yield good AC input and motor driving performances for a motor drive powered by the utility grid. Further, regenerative braking can also recover the energy back to the grid side. Besides, equipping suitable energy storage devices can enhance the reliability of motor drives.

This paper presents a bidirectional SMR fed SRM drive with a battery energy storage buffer. A constructed standard three-phase full-bridge bidirectional boost SMR establishes the well-regulated and boosted DC-link voltage for the SRM drive. It also preserves the quality of line-drawn power and sends back the recovered braking energy to the grid. For the battery energy storage system, the properly designed and controlled bidirectional interface converter preserves good charging/discharging characteristics. The proposed parallel operation strategy allows the powering of the SRM drive by the utility grid and battery simultaneously with good power-sharing performance. Further, it can improve the energy supplying reliability of the SRM drive.

\section{Author Contributions}

Chen-Wei Yang: Main author involving the measurements and the paper writing; Min-Ze Lu: Assisting the author and doing the proofreading; Wei-Ming Ma: Assisting the author and doing the proofreading; Chang-Ming Liaw: Advisor giving suggesting and doing the proofreading. 


\section{Competing Interests}

The authors have declared that no competing interests exist.

\section{References}

1. Sen PC. Principles of electric machines and power electronics. 3rd ed. New Jersey: John Wiley \& Sons; 2014.

2. Zeraoulia M, Benbouzid ME, Diallo D. Electric motor drive selection issues for HEV propulsion systems: A comparative study. IEEE Trans Veh Technol. 2006; 55: 1756-1764.

3. Vaidehi, Dhar S, Jayakumar A, Lavanya R, Kumar MD. Techno-economic assessment of various motors for three-wheeler E-auto rickshaw: From Indian context. Proceedings of the International Conference on Mechanical, Electronics and Computer Engineering (ICMECE); 2020 August 17th-19th; Seoul, South Korea. New York: Institute of Electrical and Electronics Engineers.

4. Krishnan R. Switched reluctance motor drives: Modeling, simulation, analysis, design, and applications. New York: CRC Press; 2001.

5. Kiyota K, Kakishima T, Chiba A. Comparison of test result and design stage prediction of switched reluctance motor competitive with 60-kW rare-earth PM motor. IEEE Trans Ind Electron. 2014; 61: 5712-5721.

6. Yang Z, Shang F, Brown IP, Krishnamurthy M. Comparative study of interior permanent magnet, induction, and switched reluctance motor drives for EV and HEV applications. IEEE Trans Transp Electrification. 2015; 1: 245-254.

7. Bostanci E, Moallem M, Parsapour A, Fahimi B. Opportunities and challenges of switched reluctance motor drives for electric propulsion: A comparative study. IEEE Trans Transp Electrification. 2017; 3: 58-75.

8. Vukosavic S, Stefanovic VR. SRM inverter topologies: A comparative evaluation. IEEE Trans Ind Appl. 1991; 27: 1034-1047.

9. Ye J, Emadi A. Power electronic converters for $12 / 8$ switched reluctance motor drives: A comparative analysis. Proceedings of the IEEE Transportation Electrification Conference and Expo; 2014 June 15th-18th; Dearborn, MI. New York: Institute of Electrical and Electronics Engineers.

10. Mao H, Lee CY, Boroyevich D, Hiti S. Review of high-performance three-phase power-factor correction circuits. IEEE Trans Ind Electron. 1997; 44: 437-446.

11. Kolar JW, Friedli T. The essence of three-phase PFC rectifier systems-part I. IEEE Trans Power Electron. 2013; 28: 176-198.

12. Friedli T, Hartmann M, Kolar JW. The essence of three-phase PFC rectifier systems-part II. IEEE Trans Power Electron. 2013; 29: 543-560.

13. Jang $Y$, Jovanovic MM. A comparative study of single-switch three-phase high-power-factor rectifiers. IEEE Trans Ind Appl. 1998; 34: 1327-1334.

14. Chai JY, Chang YC, Liaw CM. On the switched-reluctance motor drive with three-phase singleswitch switch-mode rectifier front-end. IEEE Trans Power Electron. 2009; 25: 1135-1148.

15. Youssef NB, Al-Haddad K, Kanaan HY. Implementation of a new linear control technique based on experimentally validated small-signal model of three-phase three-level boost-type Vienna rectifier. IEEE Trans Ind Electron. 2008; 55: 1666-1676.

16. Chen H, David N, Aliprantis DC. Analysis of permanent-magnet synchronous generator with 
Vienna rectifier for wind energy conversion system. IEEE Trans Sustain Energy. 2012; 4: 154-163. 17. Flores-Bahamonde F, Valderrama-Blavi H, Martínez-Salamero L, Maixé-Altés J, García G. Control of a three-phase AC/DC VIENNA converter based on the sliding mode loss-free resistor approach. IET Power Electron. 2014; 7: 1073-1082.

18. Hu KW, Liaw CM. Position sensorless surface-mounted permanent-magnet synchronous generator and its application to power DC microgrid. IET Power Electron. 2015; 8: 1636-1650.

19. Cacciato M, Caricchi F, Giuhlii F, Santini E. A critical evaluation and design of bi-directional DC/DC converters for super-capacitors interfacing in fuel cell applications. Proceedings of IEEE Industry Applications Conference; 2004 October 3rd-7th; Seattle, WA, USA. New York: Institute of Electrical and Electronics Engineers.

20. Zhang Z, Thomsen OC, Andersen MA. Optimal design of a push-pull-forward half-bridge (PPFHB) bidirectional DC-DC converter with variable input voltage. IEEE Trans Ind Electron. 2011; 59: 2761-2771.

21. Khan MA, Ahmed A, Husain I, Sozer Y, Badawy M. Performance analysis of bidirectional DC-DC converters for electric vehicles. IEEE Trans Ind Appl. 2015; 51: 3442-3452.

22. Forouzesh M, Siwakoti YP, Gorji SA, Blaabjerg F, Lehman B. Step-up DC-DC converters: A comprehensive review of voltage-boosting techniques, topologies, and applications. IEEE Trans Power Electron. 2017; 32: 9143-9178.

23. Nadeem F, Hussain SS, Tiwari PK, Goswami AK, Ustun TS. Comparative review of energy storage systems, their roles, and impacts on future power systems. IEEE Access. 2018; 7: 4555-4585.

24. De La Fuente DV, Rodríguez CL, Garcerá G, Figueres E, González RO. Photovoltaic power system with battery backup with grid-connection and islanded operation capabilities. IEEE Trans Ind Electron. 2012; 60: 1571-1581.

25. Rezkallah M, Hamadi A, Chandra A, Singh B. Design and implementation of active power control with improved $P \& O$ method for wind-PV-battery-based standalone generation system. IEEE Trans Ind Electron. 2017; 65: 5590-5600.

26. Prasanna UR, Xuewei P, Rathore AK, Rajashekara K. Propulsion system architecture and power conditioning topologies for fuel cell vehicles. IEEE Trans Ind Appl. 2014; 51: 640-650.

27. Jayakumar A, Chalmers A, Lie TT. Review of prospects for adoption of fuel cell electric vehicles in New Zealand. IET Electr Syst Transp. 2017; 7: 259-266.

28. Monteiro V, Pinto JG, Afonso JL. Operation modes for the electric vehicle in smart grids and smart homes: Present and proposed modes. IEEE Trans Veh Technol. 2015; 65: 1007-1020.

29. Masrur MA, Skowronska AG, Hancock J, Kolhoff SW, McGrew DZ, Vandiver JC, et al. Militarybased vehicle-to-grid and vehicle-to-vehicle microgrid-System architecture and implementation. IEEE Trans Transport Electrific. 2017; 4: 157-171.

30. Jabbour N, Mademlis C. Supercapacitor-based energy recovery system with improved power control and energy management for elevator applications. IEEE Trans Power Electron. 2017; 32: 9389-9399. 
JEPT 2021; 3(2), doi:10.21926/jept.2102016

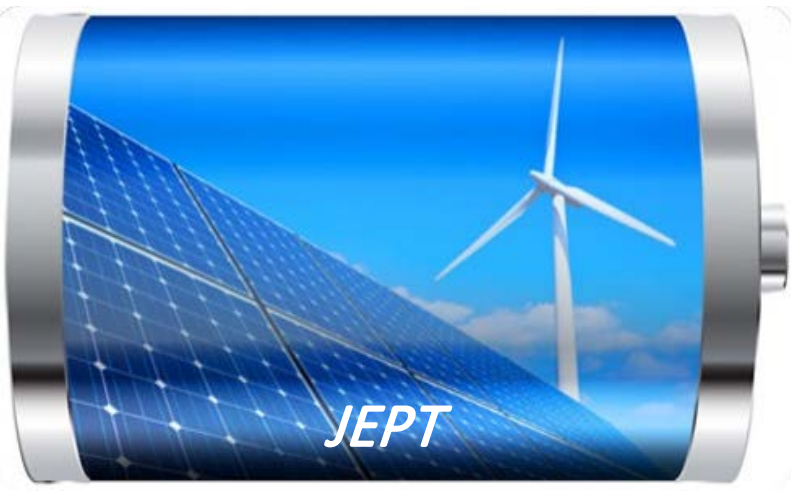

Enjoy JEPT by:

1. Submitting a manuscript

2. Joining in volunteer reviewer bank

3. Joining Editorial Board

4. Guest editing a special issue

For more details, please visit:

$\underline{27}$ 